\title{
REPRESENTAÇÕES SOCIAIS DE DOCENTES SOBRE RELAÇÕES ÉTNICO-RACIAIS NA EDUCAÇÃO BÁSICA NA AMAZỐNIA
}

\author{
Raquel Amorim Santos \\ Joana d'Arc de Vasconcelos Neves \\ Morgana da Silva Pereira
}

\begin{abstract}
Resumo
Este estudo analisa as representações sociais de docentes sobre as relações étnico-raciais na educação Básica a partir do Projeto de Extensão da UFPA em Bragança - Pará (PA). A metodologia pautou-se na abordagem qualitativa Tridimensional das Representações Sociais com base em Moscovici (1978). Para coleta de dados utilizou-se questionário com perguntas semiestruturadas. A amostragem foi constituída de 12 docentes da educação básica que participaram das ações extensionistas. $\mathrm{Na}$ análise utilizou-se o dialogismo discursivo de Bakhtin (2011). Os resultados demonstraram que os processos de formação de professores são fundantes para a [re]construção de práticas pedagógicas que visem o enfrentamento do racismo, discriminação e preconceito racial, de modo a contribuir para a construção da identidade positiva de afro-brasileiros na escola básica. Conclui-se que a formação continuada contribui para que os professores ressignifiquem seus conceitos acerca da diversidade étnica e práticas pedagógicas, voltadas para a promoção da igualdade étnicoracial.
\end{abstract}

Palavras-chave: representação social; relações étnico-raciais; formação docente.

\section{TEACHERS' SOCIAL REPRESENTATIONS OF ETHNIC-RACIAL RELATIONS IN BASIC EDUCATION IN THE AMAZON}

\begin{abstract}
The social representations of teachers about Ethnic-Racial Relations in Basic Education were analyzed at UFPA Extension Project in Bragança - PA. The methodology was based on the qualitative approach and on the Tridimensionality of Social Representations based on Moscovici (1978), using as a data collection technique the questionnaire with semi-structured questions. Sampling was made up of 12 teachers from Basic Education who participated in extension activities. The analysis was made on the basis of the discursive dialogism of Bakhtin (2011). The main results demonstrated that the processes of teacher training are foundations for the [re] construction of pedagogical practices aimed at confronting racism, discrimination and racial prejudice, in order to contribute to the construction of the positive identity of Afro-Brazilians in the school basic. We conclude that continuing education contributes to teachers' reconceptualization of ethnic diversity and pedagogical practices aimed at promoting ethnic-racial equality.

Keywords: social representation; ethnic racial relations; teacher training.
\end{abstract}

\section{REPRESENTACIONES SOCIALES DE LOS DOCENTES SOBRE LAS RELACIONES ÉTNICO-RACIALES EN LA EDUCACIÓN BÁSICA EN LA AMAZONÍA}

\begin{abstract}
Resumen
Las representaciones sociales de los docentes sobre las relaciones étnico-raciales en la educación básica se analizaron a partir del Proyecto de extensión UFPA en Bragança - PA. La metodología se basó en el enfoque cualitativo y la tridimensional de las representaciones sociales basadas en Moscovici (1978), utilizando un cuestionario con preguntas semiestructuradas como técnica de recolección de datos. La muestra estuvo conformada por 12 docentes de Educación Básica que participaron en las acciones de extensión. El análisis
\end{abstract}


se realizó en base al diálogo discursivo de Bakhtin (2011). Los principales resultados demostraron que los procesos de formación docente son fundamentales para la [re] construcción de prácticas pedagógicas que tienen como objetivo enfrentar el racismo, la discriminación y los prejuicios raciales, a fin de contribuir a la construcción de la identidad positiva de los afrobrasileños en la escuela básica. Llegamos a la conclusión de que la educación continua contribuye a que los maestros reformulen sus conceptos sobre la diversidad étnica y las prácticas pedagógicas, destinadas a promover la igualdad étnico-racial.

Palabras clave: representación social; relaciones étnico-raciales; formación del profesorado.

\section{INTRODUÇÃO}

No presente estudo são analisadas as representações sociais (RS) de docentes sobre as relações étnico-raciais na educação básica a partir do Projeto de Extensão da Universidade Federal do Pará (UFPA) sobre Formação de Professores para a Educação das Relaçooes Étnico-Raciais e para o Ensino de História e Cultura Afro-brasileira e Africana na Educação Básica em Bragança-P A (2017-2018).

O projeto objetivava promover a formação de professores para o ensino de História e Cultura Afro-Brasileira e Africana, e para educação nas relações étnico-raciais, com vista à sensibilização e à construção de estratégias para melhor equacionar questões ligadas ao combate às discriminações raciais. A formação envolveu professores da Educação Infantil, do Ensino Fundamental e da Educação de Jovens e Adultos (EJA) em diferentes atividades, como: encontros pedagógicos, ciclo de palestras, oficinas de confecção de jogos, brinquedos e brincadeiras tradicionais voltados a temática, mostra de longas e curtas metragens, teatro de fantoche e marionete com temáticas sobre cultura africana e afro-brasileira, consciência negra, identidade e roda de leitura sobre livros de lendas africanas (SANTOS, 2017).

Subentendemos que as práticas pedagógicas acerca das relações étnico-raciais são essenciais para a constituição de uma sociedade antirracista e que a escola contribui significativamente para a formação de sujeitos éticos, conscientes da diversidade étnica do Brasil que respeitem e valorizem a diversidade. Nessa perspectiva, é de suma importância compreender os fatores subjacentes e os sentidos que os professores construíram acerca das relações étnico-raciais a partir do Projeto de Extensão. Assim, nos inquietamos e questionamos: quais as representações sociais de professores sobre as relações étnico-raciais na educação básica a partir do Projeto de Extensão da UFPA e seus reflexos na prática pedagógica de professores da educação básica.

Partimos do pressuposto que as RS apresentam concepções a respeito de pessoas e objetos, visto que com consciência de si e daqueles que os cercam, as pessoas formam concepções do que encontram em sua volta, haja vista que elas conseguem:

[...] incutir um sentido ao comportamento, integrá-lo numa rede de relações em que está vinculado ao seu objeto, fornecendo ao mesmo tempo as noções, as teorias e os fundos de observação que tornam essas relações estáveis e eficazes. (MOSCOVICI, 1978, p. 49).

As RS encontram-se inseridas nos grupos sociais e contexto histórico de cada época, refletindo suas teorias e relações sociais, como afirma Jodelet (1989, p. 28), "A Teoria da Representação Social é uma forma de conhecimento, socialmente elaborada e partilhada, com objetivo prático, e que contribui para a construção de uma realidade comum a um conjunto social".

A partir desse entendimento, objetivamos analisar as representações sociais de professores acerca das relações étnico-raciais a partir do Projeto de Extensão da UFPA e suas implicações para a prática pedagógica como professores da educação básica. Para tanto, buscamos: a) identificar o processo de formação docente para a educação nas relações étnico-raciais; b) analisar os sentidos e os significados das relações étnico-raciais construídos pelos os professores que participaram da formação; e c) diagnosticar as implicações/atitudes geradas a partir das representações sobre as relações étnico-raciais na prática pedagógica dos professores da educação básica em Bragança-PA? 


\section{PERCURSO METODOLÓGICO}

O campo teórico das representações sociais de Moscovici (1978) foram fundantes para apreendermos os sentidos atribuídos pelos professores sobre as relações étnico-raciais e as implicações nas práticas docentes, visto que o seu construto teórico possibilita ao pesquisador articular a produção de sentidos sobre um dado fenômeno às atitudes geradas a partir dessa construção.

Trata-se de um campo teórico que compreende que as informações, as imagens e as atitudes se configuram como dimensões distintas de um mesmo e único processo pelo qual o ser humano expressa o seu pensamento (MOSCOVICI, 1978).

A informação corresponde ao conjunto de conhecimentos que um determinado grupo tem sobre determinado objeto. O campo da Representação remete-nos a imagens e modelos sociais acerca de um aspecto específico do objeto e a atitude que, por sua vez, coincide com determinadas posições adotadas a respeito de um objeto/situação (MOSCOVICI, 1978). Tais dimensões articulam-se aos contextos socioculturais dos grupos que, dessa maneira, apresentam variações quanto aos níveis de conhecimentos e representações.

Dessa forma, ao articular ao campo teórico de Moscovici (1978), buscamos apresentar as RS a partir da tridimensionalidade que as constituem: a informação, a imagem e a atitude, configurando-as com o campo representacional constituidor do processo de categorização deste trabalho. Assim, no campo das informações serão apresentadas as experiências dos professores no seu processo de formação; nas imagens, os sentidos construídos em torno das relações étnicoraciais; e, por fim, no campo das atitudes serão apresentadas as práticas pedagógicas geradas a partir do projeto, conforme Tabela 1 a seguir:

Tabela 1: Configuração do campo representacional

\begin{tabular}{l|l}
\hline INFORMAÇÕES & Formação no Programa \\
\hline IMAGENS & Sentidos construídos \\
\hline ATITUDES & Práticas Pedagógicas \\
\hline
\end{tabular}

Fonte: Elaborada pelas autoras/2019.

O estudo foi realizado com uma amostra de $20 \%$ de professores da educação básica do Município de Bragança-Pará, selecionados dentre um total de 60 professores que participaram das formações propostas pela UFPA a partir do Projeto de Extensão sobre Formação de Professores para a Educação das Relações Étnico-Raciais e para o Ensino de História e Cultura Afro-Brasileira e Africana na Educaşão Básica em Bragança-PA.

Para a realização da coleta de dados, inicialmente, entramos em contato com a Secretaria Municipal de Educação (SEMED), por meio da coordenação da Igualdade Racial para que fosse disponibilizado os nomes de professores com suas respectivas escolas e as fichas de frequências dos encontros realizados durante o Projeto de Extensão da UFPA. Posteriormente, selecionados os professores, entramos em contatos por meio de mensagens para agendarmos um encontro presencial. Todavia, por conta da indisponibilidade de alguns, optamos também pela aplicação do instrumento de questionário via e-mail.

Os critérios de seleção dos participantes foram: a) professores da rede municipal de ensino que realizaram práticas pedagógicas acerca das relações étnico-raciais em escolas de educação básica em Bragança-PA; b) professores que obtiveram frequência 75\% de participação no projeto. Para preservar a identidade dos professores que participaram da pesquisa, optamos por identificá-los 
por meio da letra $\mathrm{P}$ e sua respectiva numeração; c) professores que se disponibilizaram a participar da pesquisa. Na Tabela 2, descrevemos o perfil dos professores.

Tabela 2: Perfil de professores

\begin{tabular}{c|c|c|c|c|c}
\hline $\begin{array}{c}\text { Professor } \\
\text { /a }\end{array}$ & Gênero & $\begin{array}{c}\text { Raça/Cor } \\
\text { autodeclaração }\end{array}$ & Formação & Local de Trabalho & $\begin{array}{c}\text { Tempo de } \\
\text { Trabalho }\end{array}$ \\
\hline P1 & Masc. & Preta & Graduação & Área do Campo & $\begin{array}{c}\text { Superior a } \\
15 \text { anos }\end{array}$ \\
\hline P2 & Fem. & Amarela & Pós-Graduação & Área do Campo & $05-10$ anos \\
\hline P3 & Fem. & Parda & Pós-Graduação & Ambos & $\begin{array}{c}\text { Menos de 05 } \\
\text { anos }\end{array}$ \\
\hline P4 & Fem. & Parda & Graduação & Área do Campo & $05-10$ anos \\
\hline P5 & Fem. & Parda & Graduação & Área Urbana & $\begin{array}{c}\text { Superior a } \\
15 \text { anos }\end{array}$ \\
\hline P6 & Fem. & Preta & Pós-Graduação & Área Urbana & $10-15$ anos \\
\hline P7 & Fem. & Parda & Pós-Graduação & Área Urbana & $10-15$ anos \\
\hline P8 & Fem. & Preta & Graduação & Ambos & $\begin{array}{c}\text { Superior a a } \\
15 \text { anos }\end{array}$ \\
\hline P9 & Fem. & Preta & Pós-Graduação & Área Urbana & $10-15$ anos \\
\hline P10 & Fem. & Branca & Pós-Graduação & Área Urbana & $10-15$ anos \\
\hline P11 & Fem. & Branca & Pós-Graduação & Área do Campo & $05-10$ anos \\
\hline P12 & Fem. & Parda & Graduação & Área Urbana & $10-15$ anos \\
\hline Fo
\end{tabular}

Fonte: Elaborada pelas autoras com base no Questionário/2017.

Essa Tabela possibilita perceber que o número de mulheres (11) é consideravelmente maior que o número de homens (1) que aceitaram contribuir com a pesquisa. Igualmente é perceptível que todos têm ensino superior e uma parcela considerável (7) têm cursos de pós-graduação e atua, em média, 10 anos como professor.

Quanto à autodeclaração de cor/raça dos professores, adotamos as categorias do Instituto Brasileiro de Geografia e Estatística (IBGE). Assim, a Tabela 2 revela que a categoria parda apresenta maior número de autodeclaração, sendo indicada por 5 professores. Em seguida, temos a categoria preto com 4 identificações, branco com 2 apontamentos e amarelo com 1 designação. Não houve referências à categoria indígena.

De acordo com Salles (1988), a categoria parda refere-se aos mestiços. Constituindo-se como palavra ambígua, de uso generalizado, ela engloba sujeitos de diferentes processos de miscigenação. Guimarães (1999) ressalta que a classificação de pessoas a partir de grupos de cores é resultado de ideologias raciais, considerando que os significados atribuídos às cores estão além da pigmentação da pele, perpassando por hierarquizações sociais, preconceito, discriminação e racismo. Nesse sentido, corrobora que raça é uma categoria política pois possibilita a organização de resistência ao racismo e analítica por revelar que as discriminações e desigualdades são raciais e não de "classe". (GUIMARÃES, 2002, p. 50).

Munanga (2016) destaca a ressignificação do conceito de raça, como uma construção social, cultural e política, estabelecida por meio de relações sociais, contrapondo-se a premissa de raça como classificação dos sujeitos, em inferiores e superiores, derivada da perspectiva biológica do século XIX. Schwarcz (2012, p. 115) afirma que raça no Brasil sempre foi uma questão privada que influencia a ordem pública. Nessa sociedade marcada pela desigualdade e pelos privilégios, "a raça" fez e faz parte de uma agenda nacional pautada por duas atitudes paralelas e simétricas: a exclusão social e a assimilação cultural. Para ela, a "[...] cor virou o "somatório" de muitos elementos físicos, sociais e culturais, e parece variar conforme o dia [...]”. (idem, 2012, p.112). 
No Brasil, as relações "raciais" estão fundadas em um peculiar conceito de raça e forma de racismo, o "racismo à brasileira" (DAMATTA, 1987; GUIMARÃES, 2002; TELLES, 2003), cujas especificidades são significativas para compreender as relações entre os grupos de cor e as desigualdades associadas. Particularidades como a relação entre raça e classe social na hierarquização das pessoas (HASENBALG, 2005), ou as ideias sobre o "embranquecimento" (SKIDMORE, 2012), construídas na história das relações "raciais" brasileiras, mantêm-se atuantes (SANTOS, 2014).

Como instrumentos de coleta de dados, utilizamos a fotografia e os questionários semiestruturados. O primeiro, cuja origem pressupõe desejos individuais para congelar a imagem de um dado momento (SAYÃO, 2009). O segundo se caracteriza por apresentar “[...] um conjunto de questões pré-elaboradas" (CHIZZOTTI, 2001, p. 55), com o intuito de obter informações a respeito do tema a ser pesquisado.

O uso do registro fotográfico se fez no sentido de capturar as imagens das práticas pedagógicas que correspondem às ações dos professores, que participaram da formação, em suas atividades de sala de aula junto aos seus alunos. Já o questionário foi constituído de dezoito questões, previamente elaboradas que ajudaram a traçar o perfil identitário e profissional dos professores e de suas respectivas escolas, assim como para identificar os sentidos atribuídos em seus discursos sobre as relações étnico-raciais.

Configurado no campo representacional na tridimensionalidade, os dados foram analisados com base no dialogismo discursivo de Bakhtin (2011), em que buscamos destacar os enunciados que articulam as dimensões, construindo um percurso analítico deste estudo, conforme a Figura 1 a seguir:

Figura 1: Percurso de análise da pesquisa

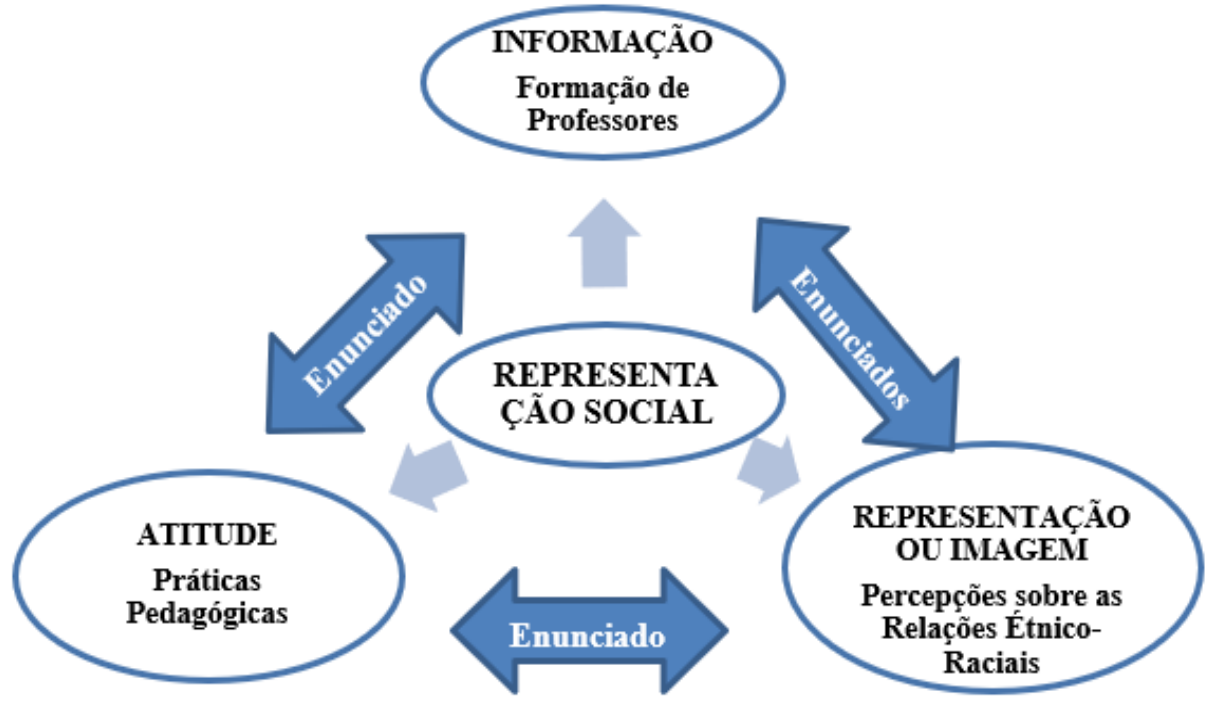

Fonte: Elaborado pelas autoras/2018

A articulação desse campo representacional entre as RS e o dialogismo bakthiniano se justifica na medida em que se compreende que cada enunciado carrega um sentido único e evidencia a posição de seu enunciador; ele é sempre dialógico por manter relações (in)diretas com outros enunciados. O dialogismo discursivo não se limita a linguagem oral e escrita, mas permeia 
todas as formas de comunicação existentes. Em seguida, apresentamos o percurso da análise deste estudo.

Assim, para materializar o campo representacional, expomos a seguir os elementos que configuram a tridimensionalidade das RS, ou seja, a formação de professores (informação); sentidos sobre as relações étnico-raciais (imagem) e práticas pedagógicas dos professores da educação básica voltadas para as relações étnico-raciais (atitude).

\section{DISCUSSÕES E RESULTADOS}

\section{Primeira dimensão - Campo das Informações: Formação de Professores e Relações Étnico-Raciais}

A formação de professores e as relações étnico-raciais compõem a primeira dimensão de análise e apresenta questões referentes ao processo de formação inicial e continuada de professores. Nesse sentido, os professores entrevistados responderam acerca de sua formação inicial e continuada relacionadas com as relações étnico-raciais. Partimos do princípio que a formação de professores precisa ocorrer constantemente. Para tanto, é necessário que as Universidades incluam nos projetos pedagógicos a temática das relações étnico-raciais, bem como cursos de Atualização e Especialização numa perspectiva antirracista, como assegura os dispositivos legais (Lei n. 10.639/2003 e n. 11.645/2008, entre outros), com a finalidade de atender as exigências de obrigatoriedade do ensino de história e cultura afro-brasileira, africana e indígena. Isso exige que os diferentes sistemas de ensino desenvolvam ações para atender as exigências da obrigatoriedade do ensino acerca das relações étnico-raciais e reflitam consubstancialmente a temática na perspectiva da diversidade e da formação (COELHO et al., 2014).

Percebemos nos discursos que 11 professores não tiveram em sua formação inicial uma matriz curricular que contemplasse a temática das relações étnico-raciais. Esses dados reafirmam que a formação inicial se apresenta frágil e com suportes teóricos insuficientes para a subversão de estereotipias presentes no imaginário social da escola (SANTOS, 2009; COELHO, 2006), como também refletem que a inclusão das relações étnico-raciais nas matrizes curriculares dos cursos de formação, como proposto pelo Estatuto da Igualdade Racial, pelas Diretrizes Curriculares Nacionais para a Educação das Relações Étnico-Raciais e para o Ensino de História e Cultura AfroBrasileira e Africana (DCNERER) e pelo Plano de Implementação das Diretrizes, ainda não abrange todos os cursos de formação inicial nas universidades brasileiras. A despeito da orientação da abordagem da temática "[...] em especial nas áreas de Educação Artística e de Literatura e Histórias Brasileira" (BRASIL, 2003, s. p.), esta deve ser trabalhada de maneira interdisciplinar nas diferentes áreas do conhecimento e ao longo do ano letivo.

Os professores também atribuíram significados sobre as relações étnico-raciais que construíram na formação continuada da UFPA e as implicações sobre sua prática pedagógica. Os discursos mais expressivos revelam:

[...] Me ajudou a conhecer e compreender conceitos referentes a cultura afro [...] relevantes a minha prática. (Professor 2, Questionário, 2018).

[...] Foi uma formação bastante proveitosa, interessante e que veio contribuir com minha prática pedagógica. Mostrou autores que estudam nessa linha e o estudo acerca da temática, que muitas vezes fica esquecida no meio escolar. (Professor 6, Questionário, 2018).

[...] Fundamental, eu, praticamente era analfabeta no assunto. (Professor 7, Questionário, 2018).

[...] A formação foi muito significativa para minha prática pedagógica, pois tive a oportunidade de conhecer melhor a Lei 10.639, estudar, ouvir as experiências de 
outras professoras e refletir com as professoras da UFPA sobre as pesquisas sobre essa temática e vivenciar, produzir recursos, atuar e colocar em prática com os meus alunos. Foram momentos de muito aprendizado. (Professor 11, Questionário, 2018).

Os discursos revelam que o significado da formação continuada da UFPA sobre as relações étnico-raciais apresenta um sentido de conhecimento acerca dos conceitos referente à cultura afrobrasileira, estudo acerca do aporte teórico específico sobre a temática étnico-racial, inclusive o conhecimento sobre a Lei n. 10.639/2003. Nesse sentido, a formação foi fundamental para a prática pedagógica dos professores, pois proporcionou pesquisas, estudos, vivências, produção de recursos pedagógicos, enfim, momentos de aprendizagem. É possível perceber também que um dos discursos revela que anterior a formação existia a ausência de conhecimento acerca das relações étnico-raciais.

De acordo com Candau (2012), a prática pedagógica apresenta as dimensões humana, técnica e político-social. Assim, é indispensável que os professores articulem tais dimensões em suas práticas pedagógicas, considerando que a qualidade do conhecimento e de experiências pedagógicas perpassa pelas relações sociais (SACRISTÁN, 2000), estabelecidas entre os sujeitos. Para tanto, o diálogo e as trocas de experiências entre os professores, durante os processos formativos, colaboram com a construção de novos conhecimentos e de práticas pedagógicas.

Os discursos reafirmam que a formação continuada é fundamental para prática pedagógica voltada para as relações étnico-raciais. Isso possibilita maior visibilidade à temática no âmbito escolar, tanto para aqueles que já realizavam alguma ação voltada para a temática, quanto para os professores que a desconheciam. Ao serem questionados sobre formação continuada, voltada para as relações étnico-raciais, para além do Projeto de Extensão, as respostas foram de acordo com as opções a seguir relacionadas: a) Sim, às vezes; b) Sim, regularmente; c) Raramente; d) Não; e) Outros.

Essas respostas revelam a lacuna existente no que tange à formação continuada voltada para as relações étnico-raciais, tendo em vista que metade dos entrevistados não têm qualquer tipo de formação específica para além do Projeto de Extensão. Os demais, apesar de possuírem tais formações, evidenciam que elas não ocorrem de maneira contínua ao longo do ano letivo, por vezes, elas limitam-se ao planejamento inicial das atividades letivas e próximas de datas pontuais, como informado pelos professores no momento da aplicação dos questionários. Observamos a partir dos dados que nenhum professor indicou que participa regularmente de formações sobre essa temática.

Entretanto, o campo da formação de professores tem importância fundamental na formação dos docentes, pois dota os sujeitos de variados pontos de vista para uma ação contextualizada, oferecendo perspectivas de análise para que os professores compreendam os contextos históricos, sociais, culturais e organizacionais (PIMENTA, 2008).

Nesse cenário, é perceptível que a maioria dos professores não está preparada teórica e metodologicamente para pautar suas ações de maneira favorável para o trato com as questões étnico-raciais. No campo educacional, a ausência dessa formação pode inviabilizar práticas pedagógicas que contemple a diversidade étnico-racial (SANTOS, 2009). Daí a necessidade de se insistir e investir para que os professores, além da sólida formação na área específica de atuação, recebam formação que os capacite não só a compreender a importância das questões relacionadas à diversidade étnico-racial, mas a lidar positivamente com elas e sobretudo criar estratégias pedagógicas que possam auxiliar a reeducá-las (BRASIL, 2003).

Gomes (2005) ratifica a necessidade de serem abordados, durante a formação de professores, as concepções sobre racismo, discriminação racial e preconceito, pois, dessa maneira, 
os professores teriam subsídios teórico para compreenderem como o racismo brasileiro constituise e identificá-lo no âmbito da escola.

Nessa perspectiva, Santos (2009, p. 91) afirma:

[...] a formação de professores é basilar para a construção de homens e mulheres atuantes em práticas curriculares plural [...]. Neste sentido, as instituições de Ensino Superior devem repensar o currículo, no sentido de formar profissionais que tenham condições de atuar na sala de aula de forma contextualizada [...].

Nessa perspectiva, o trabalho do professor não corresponde apenas aos conteúdos específicos de áreas do conhecimento. Suas práticas devem estar pautadas nas especificidades do contexto que seus alunos fazem parte, bem como de suas culturas, conhecimentos e características que lhes são próprias. Dessa forma, os processos de formação implicam diretamente nos níveis de informação dos professores acerca da temática, quanto maior o nível de aprofundamento teórico (informação) nas formações, maior consciência os professores terão sobre a necessidade de reconhecer e valorizar a história e cultura afro-brasileira e, assim, contribuir para possibilitar a desconstrução de estereótipos negativos em relação à população negra.

O significado da formação continuada da UFPA sobre as relações étnico-raciais revela um sentido de conhecimento acerca da cultura afro-brasileira com base em aporte teórico específico sobre a temática e a legislação antirracista, o que possibilitou o desenvolvimento de pesquisas, estudos, vivências, produção de recursos pedagógicos que contribuem para a prática pedagógica.

Nesse sentido, podemos compreender que os professores foram apresentados ao Projeto de Extensão com um nível de informação sobre as relações étnico-raciais, em sua maioria, ínfimos, considerando que a maioria dos professores afirmou que, em seus processos de formação inicial e continuada, não aconteceram discussões sobre a temática ou que aconteceu de forma breve, sendo insuficientes para os professores abordarem a temática étnico-racial no cotidiano escolar, desde a seleção de temas no que tange ao currículo até a preocupação com recursos didáticos.

A partir do significado da formação inicial e continuada, a seguir analisamos a percepção de professores sobre as relações étnico-raciais.

\section{Segunda dimensão - Campo dos sentidos e imagem: Relações Étnico-Raciais}

A segunda dimensão correlaciona-se aos sentidos que os professores atribuem às relações étnico-raciais e à própria formação nesse campo, correspondente à dimensão das imagens que fazem parte da estrutura tridimensional das representações sociais (MOSCOVICI, 1978).

Para abordarmos o significado das relações étnico-raciais, questionamos: para você o que significa relações étnico-raciais? As respostas mais expressivas atribuídas pelos professores revelam:

[...] Representa relações entre pessoas de forma respeitável, isso vale para qualquer impasse social como: homossexualidade, religião, política. (Professor 4, Questionário, 2018).

[...] É a reeducação entre brancos e negros, é a garantia de direitos iguais [...]. (Professor 7, Questionário, 2018).

[...] É essa mistura de etnias, de cor, de pessoas que foi construído nessa relação de poder ao longo do processo histórico. (Professor 9, Questionário, 2018).

[...] A luta contra diferentes formas de discriminação, entre elas, a racial. (Professor 11, Questionário, 2018).

[...] Conhecimento através de novas culturas diversificadas. (Professor 12, Questionário, 2018).

Os enunciados revelam sentidos de relações respeitosas sem distinção de grupos como a homossexualidade (homoafetividade), religião, política. Significa também a reeducação entre 
brancos e negros, a igualdade de direitos, a luta contra diferentes formas de discriminação e o conhecimento sobre culturas diversificadas. Com isso, constatamos um sentido positivo acerca do significado das relações étnico-raciais para os professores da educação básica.

Além disso, apreendemos que um dos enunciados apresenta a mistura de raças, a ideia de uma identidade mestiça, historicamente construída pelas relações de poder. Para Hasenbalg (2005) a mestiçagem do povo brasileiro deve ser encarada como o resultado da opressão racial e sexual, decorrente das relações sociais estabelecidas desde o período de colonização, tendo como consequência as desigualdades sociais entre brancos, mestiços, negros e indígenas.

A miscigenação operada no Brasil tinha como intuito uma identidade nacional baseada na superioridade branca, em tal premissa, dois aspectos centrais estavam subjacentes: o primeiro correspondendo a progressiva diminuição da população negra em relação à branca e o segundo refere-se à miscigenação, que "naturalmente" produziria uma população mais clara. Em suma, buscava-se uma identidade nacional baseada na herança de características europeias em detrimento da negra e indígena (SKIDMORE, 2012).

Munanga (2005) ressalta que embora tenha fracassado na aparência física, ficou inculcado no inconsciente da sociedade o ideal de branqueamento. Guimarães (1999, p. 53) enfatiza que o paradigma do embranquecimento "[...] foi, antes de tudo, uma maneira de racionalizar os sentimentos de inferioridade racial e cultural instilados pelo racismo científico e pelo determinismo geográfico do século XIX”.

Outro significado que emerge dos enunciados dos professores, foi sobre as relações étnicoraciais e a reeducação que e aponta para a perspectiva das DCNERER, constituindo-se como a "[...] reeducação entre brancos e negros" (BRASIL, 2003, p.13). Tal reeducação ressignifica os conceitos acerca da cultura africana e afro-brasileira, no sentido do reconhecimento e valorização da cultura e tratamento com igualdade de oportunidades e direitos em todos os segmentos sociais.

As contribuições dos afro-brasileiros e africanos foram fundantes para a formação da sociedade brasileira, desse modo, seus conhecimentos, hábitos, costumes e valores fazem parte da própria identidade nacional, assim, é de suma importância que os professores orientem suas práticas pedagógicas visando o reconhecimento e a valorização das diferenças na escola e em outros espaços sociais. Para tanto, é necessária formação de professores para a educação das relações étnico-raciais na educação básica e no ensino superior, que vise contribuir para a subversão do mito da democracia racial ${ }^{1}$, racismo, discriminação e preconceito racial cristalizados no imaginário social brasileiro, formas veladas e implícitas de potencializar as desigualdades raciais.

Os enunciados revelam, ainda, que os professores percebem as relações étnico-raciais como um importante aliado para a disseminação do respeito entre os diferentes grupos sociais, por meio do conhecimento e valorização das diferentes contribuições dos grupos étnicos, bem como para o enfrentamento no que tange as discriminações raciais.

Conforme Coelho (2006, p. 179), “[...] a discriminação é uma negação da presença”, ou seja, os sujeitos discriminados tornam-se invisibilizados ou são visíveis com a admissão de fatores que amenizam sua condição racial. Apesar da existência em distintos segmentos sociais, a sociedade brasileira nega a existência de práticas racistas e discriminatórias, adotando a concepção de preconceito - enquanto atitude equivocada sobre o outro - para justificar o trato diferenciado em relação a população negra (GUIMARÃES, 1999).

De uma maneira geral, os enunciados revelam que os professores percebem a formação em relações étnico-raciais como um importante aliado para disseminação do respeito entre os diferentes grupos sociais, por meio do conhecimento e valorização das diferentes contribuições dos grupos étnicos e para o enfrentamento no que tange às discriminações raciais.

\footnotetext{
${ }^{1}$ De acordo com Hasenbalg (2005, p. 251) o Mito da Democracia Racial aponta que no Brasil não existe desigualdades raciais, a população vive de maneira democrática e com igualdade de oportunidades sociais e econômicas para todos.
}

Revista Teias v. 21 • n. 62 • jul./set. 2020 • Seção Temática Raça e Cultura 
Terceira dimensão - Atitudes: Práticas Pedagógicas voltadas para as Relações ÉtnicoRaciais

A dimensão da atitude, em nosso estudo, correspondeu à dimensão das Práticas Pedagógicas de professores a partir da formação continuada da UFPA, por meio do Projeto de Extensão, voltadas para as relações étnico-raciais. Desse modo, para além dos discursos mais expressivos, utilizaremos fotografias (SAYÃO, 2009) que dialogam com tais enunciados, com o propósito de evidenciar as práticas pedagógicas (Atitudes), desenvolvidas na escola a partir da formação do Projeto de Extensão da UFPA.

As ações que os professores realizam na sala de aula são fundantes para a construção de conhecimentos e conceitos que os alunos formulam a respeito de determinado objeto e situação, assim, elas são de suma importância para promover uma educação para as relações étnico-raciais.

De acordo com Sacristán (2000, p. 201): “[...] a estrutura da prática obedece a múltiplos determinantes, tem sua justificativa em parâmetros institucionais, organizativos, tradições metodológicas, possibilidades reais dos professores, dos meios e condições físicas existentes".

$\mathrm{O}$ autor assegura que as atividades e práticas pedagógicas não são fixas. Considerando diversos fatores que influenciam na autonomia que os professores têm na sala de aula, mas, compreendemos que essa autonomia é relativa.

Libâneo, Oliveira e Toschi (2003, p. 299) afirmam: “A autonomia da escola em face das várias instâncias sociais será sempre relativa, é preciso saber compatibilizar as decisões do sistema e as decisões tomadas no âmbito das escolas, sem desconhecer as tensões entre uma e outra".

Essa autonomia permite o gerenciamento das ações escolares tanto de cunho administrativo e financeiro quanto pedagógico, o que pode contribuir para a construção da identidade e história dos diferentes sujeitos que compõem a escola. Ao abordar sobre a prática pedagógica, questionamos aos professores: como você trabalha com a temática das relações étnicoraciais em sua prática pedagógica? A esse respeito os enunciados revelam:

[...] Através de contação de histórias, musicalidade e ritmos, vídeos e colagem. (Professor 2, Questionário, 2018).

[...] Sempre nas aulas de história ou se tiver algum momento em que precise esclarecer alguma coisa referente ao assunto. (Professor 3, Questionário, 2018).

[...] Utilizo contação de histórias, vídeos, dramatização com todos, música.

Também trabalho com elementos que surgem a partir da história. (Professor 5, Questionário, 2018).

[...] a minha prática é voltada para o modo de vida dessa comunidade, sua cultura, culinária etc. (Professor 7, Questionário, 2018).

Os enunciados evidenciam que os professores utilizam atividades lúdicas e com metodologias diversas em suas práticas pedagógicas voltadas para as relações étnico-raciais, dentre as quais: a contação de histórias, os vídeos, a corporeidade, as danças, as músicas para orientarem suas ações:

[...] A contação de história teve um destaque, pois tive oportunidade de conhecer novos contos, de como contar, o que utilizar e abordar. (Professor 4, Questionário, 2018).

[...] O teatro, a música, a dança, as brincadeiras, os brinquedos, a contação de história, tudo isso foi significativo. Mas, o fato de eu usar um simples objeto, por exemplo, a peneira e a partir daí ensinar sobre cultura, história, levar o aluno a conhecer toda a história dos seus antepassados etc. foi marcante. (Professor 7, Questionário, 2018).

[...] Gostei bastante de trabalhar com a Boneca Abayomi, associamos com escolas anexas e foi uma atividade muito boa. (Professor 8, Questionário, 2018). 
[...] Cantigas de roda, de movimentos de batuques e de corpo e de contações de histórias. (Professor 9, Questionário, 2018).

[...] As histórias e os jogos lúdicos, pois as histórias que se contam, não enfatizam todos os povos e raças, mas, apenas uma minoria. (Professor 10, Questionário, 2018).

Nessa perspectiva, os professores realizaram diversas ações em suas escolas, utilizando diferentes metodologias e objetos, sempre de forma significativa e positiva em relação aos costumes, aos conhecimentos e as contribuições de afro-brasileiros e africanos para nossa sociedade, com metodologias diferenciadas e lúdicas. Dessa forma, brincadeiras, brinquedos, cantigas, histórias e atividades afins contribuíram para as aprendizagens dos alunos.

A prática pedagógica e sua aplicabilidade na escola permeou as ações do Projeto de Extensão. Naquele momento, os professores realizavam diferentes atividades acerca das relações étnico-raciais. Desse modo, questionamos: as temáticas propostas pelo Projeto de Extensão ofereceram subsídios suficientes para sua prática pedagógica acerca das relações étnico-raciais e seus desdobramentos? Os enunciados mais expressivos revelam:

[...] As temáticas contribuíram consideravelmente com minhas práticas pedagógicas e mudou a minha maneira de olhar as situações de preconceito em sala de aula. (Professor 1, Questionário, 2018).

[...] Sim, as temáticas foram muito boas e todas nos mostraram como trabalhar a questão em classe. (Professor 3, Questionário, 2018).

[...] Sim, pois foi através das propostas do projeto que me inspiraram a trabalhar em sala de aula de forma mais dinâmica e lúdica. (Professor 6, Questionário, 2018).

[...] Sim. Com o suporte temático oferecido pelo projeto foi suficiente para desenvolver atividades na escola que antes eu tinha "medo" de fazer porque a comunidade não aceitava. Como por exemplo: Danças de origem africana, oficinas de bonecas negras. (Professor 7, Questionário, 2018).

[...] Suficientes nunca serão, mas nortearam para que pudesse buscar mais... (Professor 10, Questionário, 2018).

De acordo com os enunciados, o Projeto de Extensão contribuiu significativamente tanto para as práticas de professores quanto para a sensibilização desses sujeitos, no que tange à identificação de atitudes preconceituosas, com a compreensão de que o racismo é algo nocivo, presente na sociedade brasileira de maneira naturalizada.

Apesar dos subsídios oferecidos aos professores pelo Projeto de Extensão em relação as suas práticas pedagógicas, o P10 sublinhou a necessidade de pesquisarem e buscarem continuamente novos conhecimentos acerca da temática das relações étnico-raciais para subsidiarem suas ações, visto que, como ressalta Luiz (2013), é necessário engajamento para a desconstrução de estereótipos e concepções negativas em relação ao negro, tendo em vista que a escola constitui-se como um espaço de enfrentamento e de mudanças.

As Figuras 2 e 3 mostram algumas práticas pedagógicas voltadas para as relações étnicoraciais, especialmente a confecção pelos alunos do Jogo Mancala e Bonecas Abayomi, respectivamente. 
Figura 2: Alunos confeccionando Mancala

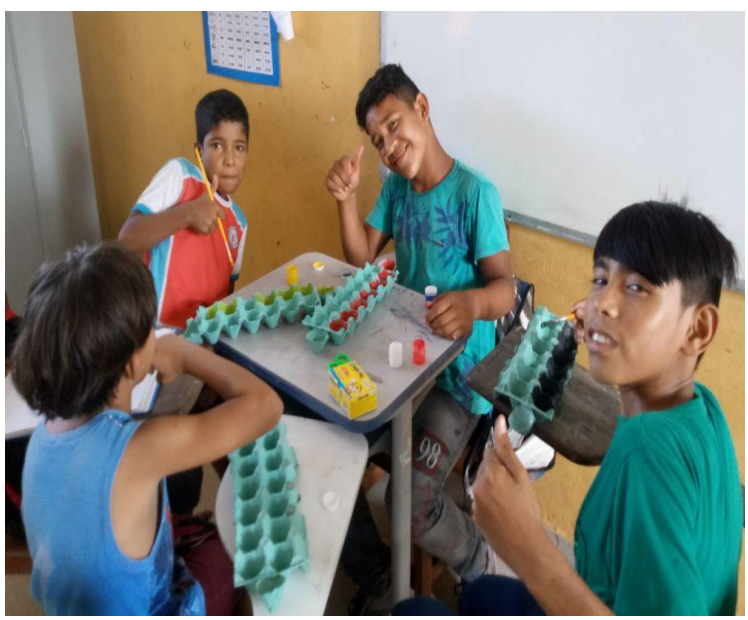

Fonte: Arquivo fotográfico pessoal dos professores da RME/2017.

Figura 3: Alunos e Bonecas Abayomi

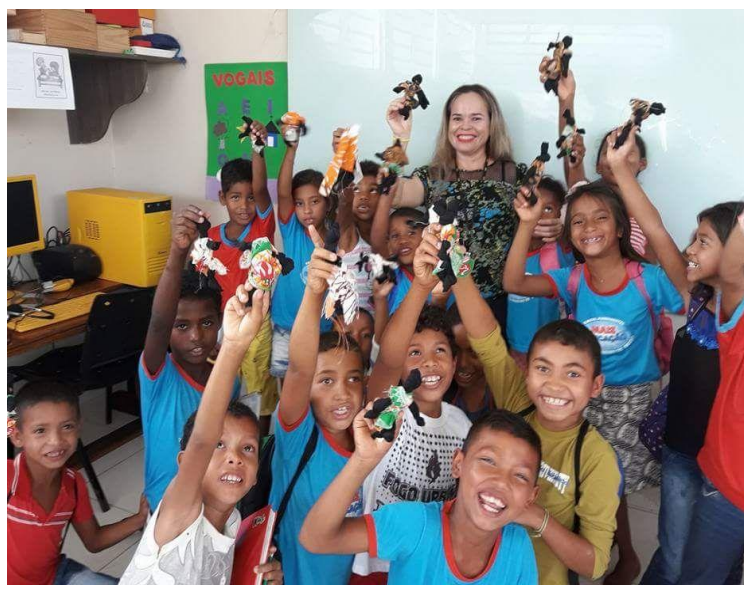

Fonte: Arquivo fotográfico pessoal dos professores da RME/2017.

Mancala é um jogo de tabuleiro africano com distintas modalidades de realização em diferentes culturas africanas; eles possibilitam trabalhar com Matemática, raciocínio lógico e estratégias (MISSAWA, 2006), podendo ser confeccionado com diferentes recursos, inclusive de forma sustentável.

As Bonecas Abayomi, por sua vez, são símbolos de resistência negra no Brasil. Suas características (sem definições específicas) têm a finalidade de evidenciar a diversidade de povos africanos e seu uso, enquanto estratégia pedagógica, de modo a resgatar tal diversidade e colaborar com a construção de "[...] identidades culturais, uma vez que, parte do princípio da ruptura de conceitos estéticos hegemônicos" (COSTA et al., 2015, p. 2) e eurocêntricos.

Essas atividades possibilitaram trabalhar de forma mais significativa e contextualizada as influências africanas e afro-brasileiras na escola em diferentes turmas, tendo em vista que as propostas apresentadas podem ser trabalhadas com públicos distintos, sendo necessárias apenas adaptações quanto às metodologias a serem abordadas. 
Nesse sentido, as propostas de atividades e discussões teóricas foram fundantes para as práticas pedagógicas dos professores, mas ainda há necessidade de ampliação das discussões acerca das relações de gênero. A esse respeito o enunciado revela: “[...] $\mathrm{Na}$ minha opinião, todas foram significativas, mas acredito que o tema "gênero" teve pouco tempo para mais e mais esclarecimentos. No geral todas foram muito boas". (Professor 3, Questionário, 2018).

É válido ressaltar que as mudanças ocorridas nas práticas pedagógicas a partir da formação continuada da UFPA foram perceptíveis, visto que nos enunciados, os professores apresentam um maior engajamento e preocupação em se trabalhar com as relações étnico-raciais, dando continuidade em ações para o enfrentamento do silenciamento acerca dessas relações na escola e reconhecem que o Projeto Extensão foi basilar para se perceber a importância que a temática tem para a sociedade brasileira.

A esse respeito questionamos: como você percebe sua prática pedagógica em relação às questões étnico-raciais antes e depois da formação continuada de professores realizada pela UFPA? Os enunciados mais expressivos anunciam:

[...] Antes não havia um trabalho voltado para estas questões, então, só se trabalhava a cultura negra no dia da consciência. Depois da formação tudo se modificou e, hoje, a proposta é de valorização. (Professor 1, Questionário, 2018). [...] Percebo que ficou mais dinâmica depois da formação, pois, antes o máximo que fazia / falava a respeito era passar vídeos e textos sobre o assunto. (Professor 2, Questionário, 2018).

[...] A prática pedagógica ficou muito melhor depois da formação, pois, aprendemos a usar os recursos disponíveis para dinamizar as aulas. (Professor 3, Questionário, 2018).

[...] $\mathrm{Na}$ verdade antes, nem existia na minha prática pedagógica questões referentes às relações étnico-raciais. Hoje, o cenário mudou e o fato de eu ter ido trabalhar na comunidade do Américo e participado da Formação Continuada de Professores, fizeram com que eu passasse a valorizar o que a comunidade tem a oferecer: história, cultura, danças, festas etc. (Professor 8, Questionário, 2018).

[...] Depois do projeto, considero que foi vista com mais atenção, antes não era vista, eu fazia por conta própria. Como os outros professores não conheciam talvez eles não valorizavam. (Professor 8, Questionário, 2018).

Os enunciados revelam que o trabalho sobre as relações étnico-raciais se tornou mais presente ao longo das práticas de professores da educação básica, deixando de ser realizado somente em datas e conteúdos pontuais, bem como possibilitou maior dinamismo nas aulas e valorização das contribuições dos africanos e afro-brasileiros para a constituição do Brasil.

Assim, é importante a ressignificação de conceitos e valores do próprio professor quanto no trato com a temática das relações étnico-raciais, bem como nas ações coletivas com a comunidade escolar para que haja mudanças significativas nas relações étnico-raciais na escola.

Anterior à formação continuada do Projeto de Extensão sobre relações étnico-raciais, as ações eram individuais, sendo invisibilizadas e não valorizadas pelos demais professores, como enunciado pelo P8; contudo, tal percepção mudou e os professores, após as formações realizadas em suas escolas, passaram a trabalhar com o objetivo comum de promover a educação para a igualdade racial a partir de ações de reconhecimento e valorização da cultura afro-brasileira e africana. Tal enunciado evidencia que o Projeto de Extensão contribuiu (in)diretamente para a ressignificação de conceitos e práticas pedagógicas dos professores.

Santos (2009, p. 152) corrobora que os agentes sociais que integram as escolas, em especial os professores, são essenciais para a desconstrução do mito da democracia racial e para a promoção do reconhecimento e valorização da "[...] identidade, história e cultura do povo negro". 

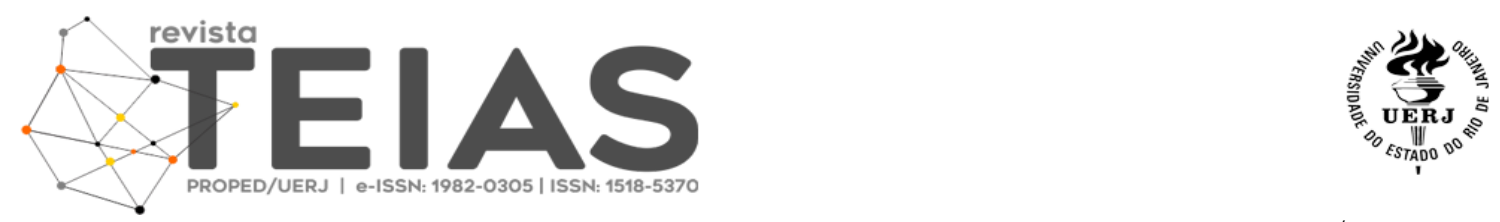

DOI: $10.12957 /$ teias. $\%$ Y.49725

É possível perceber que a partir da formação continuada da UFPA, por meio do Projeto de Extensão, as escolas realizaram diversas atividades pedagógicas, envolvendo as relações étnicoraciais, tais como: Desfile de Beleza Negra (Figuras 4 e 5) que contou com a participação de todos os alunos e possibilitou o empoderamento de suas identidades e pertencimento étnico-racial. Tal momento foi resultado do trabalho realizado por todos os professores do ensino fundamental, ao longo do ano letivo de 2017.

Figura 4: Encenação teatral

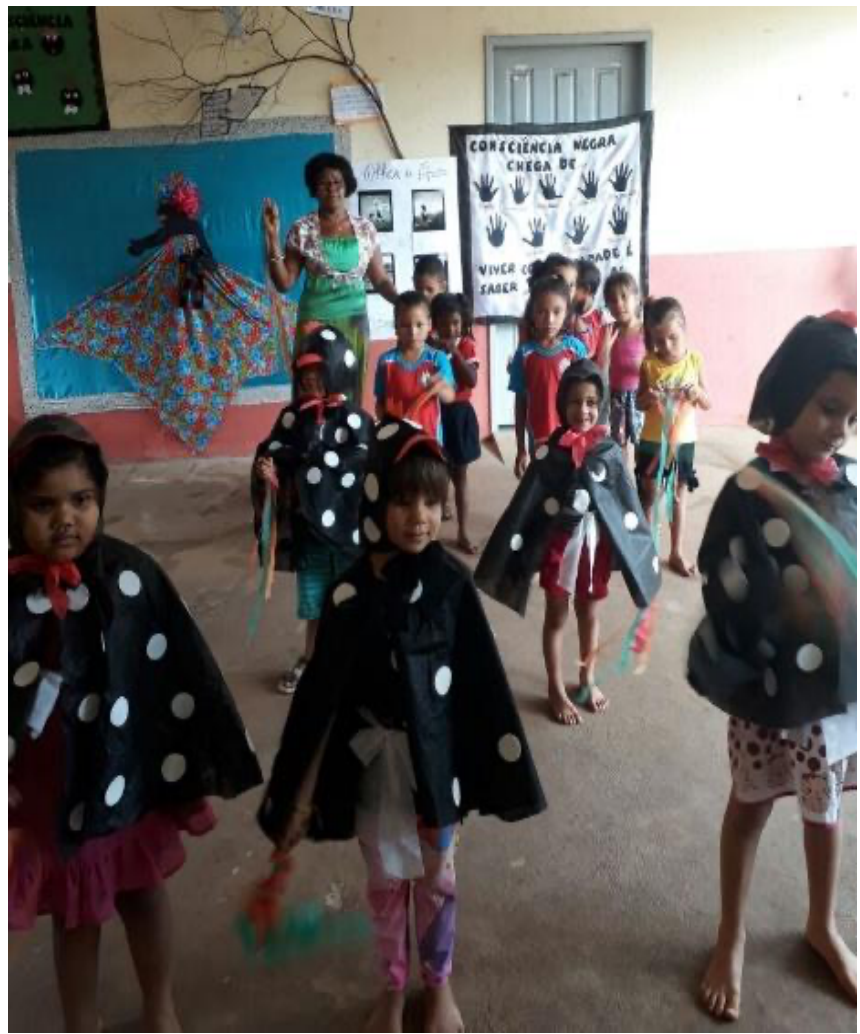

Fonte: Arquivo fotográfico pessoal dos Professores da RME/2017 
Figura 5: Desfile Beleza Negra

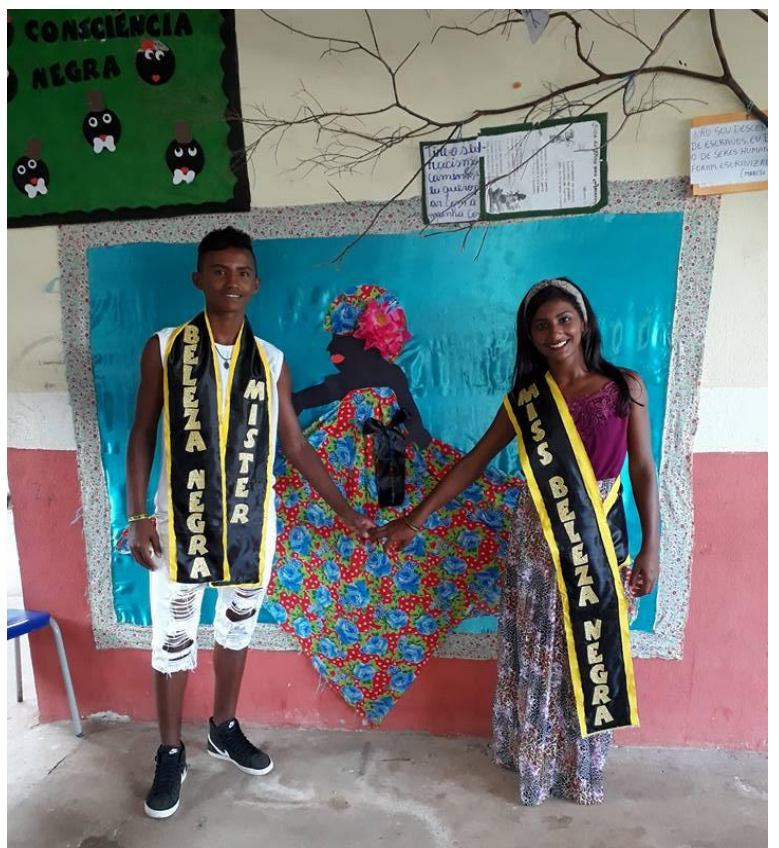

Fonte: Arquivo fotográfico pessoal dos Professores da RME/2017

As práticas pedagógicas adotadas pelos professores desta instituição atendem ao que a Lei n. 10.639/2003 dispõe, em relação às distintas contribuições dos negros para a formação da sociedade brasileira, "[...] nas áreas social, econômica e política pertinentes à História do Brasil" (BRASIL, 2003, p. 1).

Mesmo tendo realizado práticas que contemplam a obrigatoriedade do ensino de história e cultura afro-brasileira e africana, de maneira interdisciplinar e constante, no currículo, o professor desconhece os mecanismos legais que subsidiam suas ações. O desconhecimento da Lei n. 10.639/2003 implica na realização de práticas pedagógicas fragilizadas que deem suporte para a efetivação da educação das relações étnico-raciais na sala de aula, conforme asseguram as DCNERER, Estatuto da Igualdade Racial e afins.

Santos (2009, p. 146) afirma que a Lei: “[...] supera a visão de que a cultura negra no Brasil é subaproveitável, isto é, se resume à mera contribuição e traz para o cerne do debate a ideia de participação, constituição e configuração da sociedade brasileira pela ação das diversas etnias africanas e seus descendentes".

Dessa maneira, quando tal dispositivo legal é implementado por meio das práticas pedagógicas, entre outras possibilidades pedagógicas, oferece inúmeras contribuições para o enfrentamento do racismo, discriminação e preconceito na sociedade, enfatizando o reconhecimento e valorização das heranças deixadas pelos povos africanos.

De acordo com os professores, a formação continuada proposta pelo Projeto de Extensão contribuiu significativamente para as suas práticas pedagógicas acerca das relações étnico-raciais, bem como para a sensibilização desses sujeitos em relação à discriminação racial, o racismo e o preconceito na sociedade. Os professores também revelaram a necessidade de realizarem pesquisas sobre a temática e de subsidiarem suas ações com dispositivos oficiais, a exemplo da Lei n. $10.639 / 2003$.

Em suma, tais atitudes são positivas para uma prática pedagógica comprometida com a formação de cidadãos que reconhecem a diversidade étnica e cultural de sua nação, sendo reflexo das dimensões da informação e de imagens, subjacentes a estrutura das representações sociais. 


\section{CONSIDERAÇÕES FINAIS}

As dimensões da informação, imagem e atitudes, bem como as objetivações e ancoragens, que integram as RS foram basilares para a percepção acerca das representações sociais de professores sobre as relações étnico-raciais a partir do Projeto de Extensão da UFPA.

Com base na tridimensionalidade de Moscovici (1978), na Figura 6, apresentamos as dimensões que emergiram deste estudo.

Figura 6: Dimensões das representações sociais

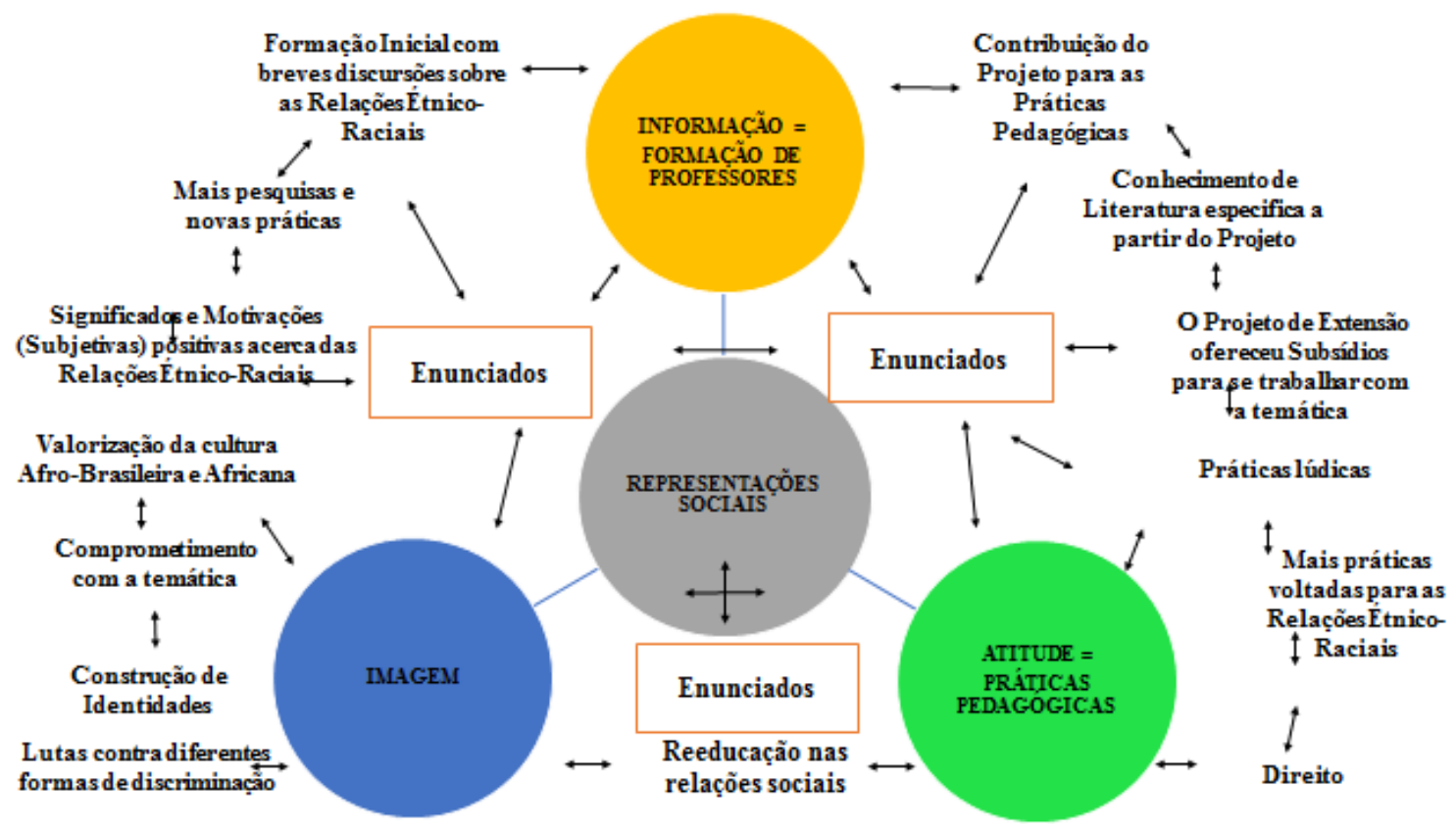

Fonte: Elaborado pelas autoras com base no questionário/2018

Percebemos que antes de tal formação, grande parte dos professores não tinha uma concepção concreta acerca das relações étnico-raciais, por conta das lacunas sobre a temática, deixadas em sua formação inicial. Desse modo, é notório as implicações dos processos de formação inicial e continuada para a construção de imagens e significados acerca de um determinado tema, em nosso caso, em relação a educação para as relações étnico-raciais.

Assim, constatamos que a dimensão da Informação apresenta níveis distintos, por conta das referências que os professores adquiriram ao longo de seus processos de formação docente. Desse modo, a formação continuada da UFPA possibilitou o aprofundamento teórico acerca das relações étnico-raciais e ressignificação de conceitos que tendem em muitos casos a serem reproduzidas sem a reflexão necessária sobre o assunto.

Com relação à dimensão da representação/imagem dos professores que circularam em torno de aspectos pessoais, culturais e de conhecimentos específicos acerca da história e cultura afro-brasileira e africana, facultaram a construção de identidades étnicas positivas, baseadas na valorização e respeito pelo outro, tendo em vista que as experiências formativas impulsionaram a sensibilização quanto a olhar o outro em sua singularidade.

No tocante à dimensão da Atitude, esta demonstrou ser positiva para a desconstrução de estereótipos e ressignificação de conceitos em relação aos negros que, historicamente, acabam por serem perpetuados frente ao desconhecimento, assim como para a promoção de uma educação 
antirracista e para a formação de sujeitos que valorizam o protagonismo dos afro-brasileiros para a consolidação do Brasil enquanto nação.

Percebemos que, a partir dos enunciados feitos pelos professores, o Projeto de Extensão contribuiu significativamente para a reeducação das relações étnico-raciais, bem como para práticas pedagógicas voltadas para a temática, dando ênfase para a valorização da cultura africana e afrobrasileira para a constituição do Brasil. Para tanto, os professores ressaltaram a ampliação de conhecimentos de literaturas específicas sobre a temática, assim como de subsídios teóricos que possibilitou o trabalho com significados e com a construção de identidades étnicas positivas.

Nesse viés, a tridimensionalidade das RS foram fundantes para a construção e ressignificação de novos conceitos acerca das relações étnico-raciais na educação básica, sobretudo dos professores que participaram do Projeto de Extensão da UFPA, haja vista que a formação propiciou suporte teórico-metodológico que influenciou nas práticas pedagógicas dos professores, ocasionando em ações favoráveis para o enfrentamento do racismo, discriminações e preconceitos na escola, bem como para a construção de identidades raciais positivas.

\section{REFERÊNCIAS}

ABREU, Martha; MATTOS, Hebe. Em torno das Diretrizes curriculares nacionais para a educação das relações étnico-raciais e para o ensino de história e cultura afro-brasileira e africana: uma conversa com historiadores. Estudos Históricos, Rio de Janeiro, v. 21, n. 41, jan./jun. 2008.

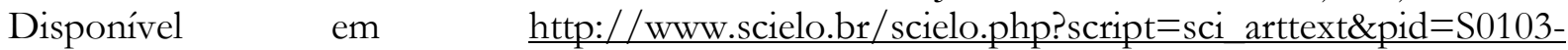
21862008000100001 . Acesso em 20 dez. 2018.

BRASIL. Lei n. 10.639, de 9 de janeiro de 2003. Altera a Lei no 9.394, de 20 de dezembro de 1996, que estabelece as diretrizes e bases da educação nacional, para incluir no currículo oficial da Rede de Ensino a obrigatoriedade da temática "História e Cultura Afro-Brasileira", e dá outras providências. Brasília, DF, Presidência da República [2003]. Disponível em http://www.planalto.gov.br/ccivil_03/leis/2003/110.639.htm. Acesso em 14 fev. 2019.

BRASIL. Lei n. 11.645, de 10 de margo de 2008. Altera a Lei n. 9.394, de 20 de dezembro de 1996, modificada pela Lei n. 10.639, de 9 de janeiro de 2003, que estabelece as diretrizes e bases da educação nacional, para incluir no currículo oficial da rede de ensino a obrigatoriedade da temática "História e Cultura Afro-Brasileira e Indígena". Brasília, DF, Presidência da República [2008]. Disponível em http://www.planalto.gov.br/ccivil 03/Ato2007-2010/2008/Lei/L11645.htm. Acesso em 14 fev. 2019.

BRASIL. Diretrizes Curriculares Nacionais para a Educaşão das Relaçôes Étnico-Raciais e para o Ensino de História e Cultura Afro-Brasileira e Africana. Brasília, DF, Ministério da Educação [2003]. Disponível em http://portal.inep.gov.br/documents/186968/484184/Diretrizes. Acesso em 18 nov. 2018.

BAKHTIN, Mikhail. Estética da criação verbal. Tradução de Paulo Bezerra. 6. ed. São Paulo: Martins Fontes, 2011.

CAMARGO, Rosana Maria de. Diversidade étnico-cultural no currículo: ações para formação de professores realizadas por dois Núcleos de Estudos Afro-Brasileiros. 122 f. Dissertação (Mestrado em Educação) - Programa de Estudos Pós-Graduados em Educação: História, Política, Sociedade, Pontifícia Universidade Católica de São Paulo, São Paulo, 2015. Disponível em https://br.123dok.com/document/z3dpd5ey-diversidade-etnico-cultural-no-curriculo-acoespara-formacao-de-professores-realizadas-por-dois-nucleos-de-estudos-afro-brasileiros-paulistas2003-2013-mestrado-educacao-historia-politica-sociedade.html. Acesso em 14 fev. 2019.

CANDAU, Vera Maria Ferrão (org.). Reinventar a escola. 8. ed. Petrópolis: Vozes, 2012. 
COELHO, Wilma de Nazaré Baía. A cor ausente: um estudo sobre a presença do negro na formação de professores - Pará, 1970-1989. Belo Horizonte: Mazza Edições; Belém: Unama, 2006.

COELHO, Wilma de Nazaré Baía et al. A lei n. 10.639/2003: pesquisas e debates. São Paulo: Editora Livraria da Física, 2014.

COSTA, Fernanda Laura et al. As bonecas Abayomi e as novas sensibilidades históricas: possibilidades para uma educação anti-racista, 2015. Disponível em http://www.faculdadealfredonasser.edu.br. Acesso em 14 fev. 2019.

CHIZZOTTTI, Antônio. Pesquisa em ciências humanas e sociais. 5. ed. São Paulo: Cortez, 2001.

DAMATTA, Roberto. Relativizando: uma introdução à antropologia social. Petrópolis: Vozes, 1987. GOMES, Nilma Lino. Educação e relações raciais: refletindo sobre algumas estratégias de atuação. In: MUNANGA, Kabengele (org.). Superando o racismo na escola. 2. ed. Brasília: Ministério da Educação, Secretaria de Educação Continuada, Alfabetização e Diversidade, 2005. p. 143-154.

GOMES, Nilma Lino; JESUS, Rodrigo Ednilson de. As práticas pedagógicas de trabalho com relações étnico-raciais na escola na perspectiva de Lei 10.639/2003: desafios para a política educacional e indagações para a pesquisa. Educar em Revista, Curitiba, v. 1, n. 47, p. 19-33, jan./mar. 2013.

GUIMARÃES. Antonio Sérgio Alfredo. Raça e os estudos de relações raciais no Brasil. Novos Estudos-CEBRAP, São Paulo, n. 54, p. 147-156, jul. 1999.

GUIMARÃES, Antonio Sérgio Alfredo. Classes, raças e democracia. São Paulo: Editora 34, 2002.

HASENBALG, Carlos. Discriminação e desigualdades raciais no Brasil. Belo Horizonte: Editora da UFMG; Rio de Janeiro: IUPERJ, 2005.

INSTITUTO BRASILEIRO DE GEOGRAFIA E ESTATÍSTICA - (IBGE). Disponível em https://www.ibge.gov.br/estatisticas/sociais/populacao/9372-caracteristicas-etnico-raciais-dapopulacao.html?=\&t=conceitos-e-metodos Acesso em 15 fev. 2018.

JODELET, Denise. Représentations sociales: un domaine en expansion. In: JODELET, Denise (ed.). Les représentations sociales. Paris: PUF, 1989. p. 31-61.

LIBÂNEO, José Carlos; OLIVEIRA, João Ferreira de; TOSCHI, Mirza Seabra. Educação escolar. políticas, estrutura e organização. São Paulo: Cortez, 2003.

LUIZ, Maria Fernanda. Educação das relações étnico-raciais: contribuições de cursos de formação continuada para professoras(es). 140 f. Dissertação (Mestrado em Educação) - Centro de Educação e Ciências Humanas, Universidade Federal de São Carlos, São Carlos, 2013.

MISSAWA, Daniela Dadalto Ambrozine. O jogo mancala como instrumento de ampliação da compreensão das dificuldades de atenção. 107 f. Dissertação (Mestrado em Psicologia) - Programa de Pós-Graduação em Psicologia, Universidade Federal do Espírito Santo, Vitória, 2006.

MOREIRA, Valdir da Silva. Currículo escolar e as relações étnico-raciais: desafios e perspectivas nos anos iniciais do ensino fundamental no município de Lucas do Rio Verde. Portal Educação. s. d. Disponível em https://www.portaleducacao.com.br/conteudo/artigos/pedagogia/curriculoescolar-e-as-relacoes-etnicos-raciais/58798. Acesso em 13 jan. 2018.

MOSCOVICI, Serge. A representação social da psicanálise. Rio de Janeiro: Zahar, 1978.

MUNANGA, Kebengele. Superando o racismo na escola. Brasília: MEC/SECAD, 2005.

MUNANGA, Kebengele. Rediscutindo a mestiçagem no Brasil: identidade nacional versus identidade negra. 3. ed. Belo Horizonte: Autêntica, 2008.

MUNANGA, Kabengele. O negro no Brasil de hoje / Kabengele Munanga, Nilma Lino Gomes. 2. ed. São Paulo: Global, 2016. 
PIMENTA, Selma Garrido. Saberes pedagógicos e atividade docente. 3. ed. São Paulo: Cortez, 2008. SACRISTÁN, Gimeno. O currículo: uma reflexão sobre a prática. 3. ed. Porto Alegre: Artmed, 2000. SALLES, Vicente. O negro no Pará: sob o regime da escravidão. 2. ed. Brasilia: Ministério da Cultura; Belém: Secretaria de Estado da Cultura; Fundação Cultural do Pará “Tancredo Neves”, 1988.

SANTOS, Raquel Amorim dos Santos. [In]visibilidade negra: representação social de professores acerca das relações raciais no currículo escolar do Ensino Fundamental em Ananindeua (PA). 182f. Dissertação (Mestrado em Educação) - Universidade Federal do Pará, Instituto de Ciências da Educação, Programa de Pós-Graduação em Educação, Belém, 2009.

SANTOS, Raquel Amorim dos Santos; SILVA, Rosângela Maria de Nazaré Barbosa e. Racismo científico no Brasil: um retrato racial do Brasil pós-escravatura. Educar em Revista, Curitiba, v. 34, n. 68, p. 253-268, mar./abr. 2018.

SANTOS, Raquel Amorim dos. Projeto de extensão formação de professores para a educação das relações étnicoraciais e para a história e cultura afro-brasileira e africana na educação básica em Bragança-P A. Belém: PróReitoria de Extensão; Universidade Federal do Pará, 2017.

SANTOS, Raquel Amorim dos Santos. Ciclo de Política Curricular do Estado do Pará (2008-2012): A Enunciação Discursiva Sobre Relações "Raciais". 272 f. Tese (Doutorado em Educação) Universidade Federal do Pará, Instituto de Ciências da Educação, Programa de Pós-Graduação em Educação, Belém, 2014.

SAYÃO, Thiago Juliano. Linguagem visual na historiografia. Indaial: Grupo Uniasselvi, 2009.

SILVA, Maria Aparecida. Formação de educadores/as para o combate ao racismo: mais uma tarefa essencial. In: CAVALLEIRO, Eliane (org.). Racismo e anti-racismo na educação: repensando a escola. São Paulo: Selo Negro, 2001. p. 67.

SKIDMORE, Thomas. Preto no branco: raça e nacionalidade no pensamento brasileiro. Rio de Janeiro: Paz e Terra, 2012.

SCHWARCZ, Lílian Moritz. Nem preto, nem branco, muito pelo contrário: cor e raça na intimidade. São Paulo: Claro Enigma, 2012.

TELLES, Edward. Racismo à brasileira: uma nova perspectiva sociológica. Rio de Janeiro: RelumeDumará: Fundação Ford, 2003.

Submetido em marco de 2020

Aprovado em junbo de 2020

\section{Informações das autoras}

Raquel Amorim Santos

Doutoranda do Programa de Pós-Graduação em Educação do Instituto de Ciências da Educação da Universidade Federal do Pará (ICED/UFPA). Técnica em Educação e Professora da Secretaria de Estado de Educação (SEDUC). 
E-mail: rakelamorim@yahoo.com.br

ORCID: http://orcid.org/0000-0003-4817-0036

Link Lattes: http://lattes.cnpq.br/3387666784015912

Morgana da Silva Pereira

Secretaria Municipal de Educação de Ipixuna -SEMED-Ipixuna

E-mail: morgan.silva.s2@gmail.com

ORCID: https://orcid.org/0000-0001-5747-7019

Link Lattes: http://lattes.cnpq.br/1530200110256370

Joana d'Arc de Vasconcelos Neves

Docente do Programa de Pós-Graduação Linguagens e Saberes da Amazônia e Professora Adjunta da Universidade Federal do Pará Campus de Bragança-PA.

E-mail: jdneves@ufpa.br

ORCID: https://orcid.org/0000-0002-3110-3649

Link Lattes: http://lattes.cnpq.br/5658289632563411 